\title{
The role of Clinical-Functional Vulnerability Index-20 to detect quality of life in older adults assisted in primary care
}

\author{
Levi Bezerra Sena ${ }^{1 * ~(1)}$, Larissa Paixão Batista' ${ }^{1}$, Flávia Fonseca Fernandes ${ }^{1}$ (1), \\ Alfredo Nicodemos Cruz Santana'
}

\begin{abstract}
SUMMARY
OBJECTIVE: To determine the cutoff point of the Clinical-Functional Vulnerability Index-20 to detect poor quality of life in the elderly in Primary Health Care.

METHODS: This cross-sectional study was carried out in Primary Health Care units of Ceilândia (DF, Brasil) between September 2019 and January 2020. Four hundred and fifty-eight individuals were included in the study and answered the Clinical-Functional Vulnerability Index-20 (IVCF-20) and the World Health Organization Quality of Life - WHOQOL-BREF (validated to access quality of life) instruments. Based on the WHOQOL-BREF answers, three subgroups were created: poor, good and undetermined quality of life. The receiver operating characteristic curve (using Youden index) showed the IVCF-20 cutoff point to detect poor quality of life (in individuals with good quality of life as the Control Group), and therefore diagnostic tests were performed.

RESULTS: The IVCF-20 cutoff point to detect poor quality of life was $\geq 11$. The area under the receiver operating characteristic curve was 0.97 (95\% Cl 0.95-0.98). The IVCF-20 diagnostic tests showed good sensitivity (88.1\%) and specificity (84.9\%).

CONCLUSIONS: The IVCF-20 $\geq 11$ detected poor quality of life adequately in the elderly in Primary Health Care. These data suggest that elderly individuals with IVCF $\geq 11$ should attend appointments more often in Primary Health Care or geriatrics collaborative care, considering the impact that quality of life can have on the elderly population's mortality.

KEYWORDS: Frail elderly. Health Services for the Aged. Frailty. Primary Health Care. Quality of Life.
\end{abstract}

\section{INTRODUCTION}

The progressive increase in the number of elderly individuals has a major impact on public health services due to the higher prevalence of chronic-degenerative diseases and functional disabilities ${ }^{1,2}$. Consequently, it is fundamental to try maintaining the functional independence and quality of life (QOL) of these elderly individuals for as long as possible.

Regarding the QOL, the World Health Organization defines it as: "an individual's perception of their position in life in the context of the culture and value systems in which they live and in relation to their goals, expectations, standards and concerns"3.
Consequently, it is a subjective term, involving aspects related to beliefs, physical, psychological, social, and environmental aspects. Thus, it is difficult to measure $\mathrm{QOL}^{3}$.

In addition, it is known that QOL in elderly individuals also works as an independent predictor for unfavorable clinical outcomes, morbidity, and mortality ${ }^{4,5}$. Accordingly, concerns with QOL of the elderly become an important component when planning actions within a health care system.

However, QOL is usually assessed by specific instruments, such as the World Health Organization Quality of Life (WHOQOL-BREF) ${ }^{6}$. This instrument is not so practical to be

\footnotetext{
'Escola Superior de Ciências da Saúde - Brasília (DF), Brasil.

*Corresponding author: levibsena@gmail.com

Conflicts of interest: the authors declare there is no conflict of interest. Funding: none.

Received on November 02, 2020. Accepted on December 10, 2020.
} 
applied in the daily life in the Primary Health Care (PHC) service, due to the time necessary for its application, when compared to the time available for the appointments ${ }^{7}$. Hence, the use of more practical questionnaires for QOL screening is an interesting proposal to be researched in the $\mathrm{PHC}^{8}$.

In this context, the Clinical-Functional Vulnerability Index20 (IVCF-20, Índice de Vulnerabilidade Clinico-Funcional) may play a role in QOL screening for the elderly in PHC. This instrument was created and validated in Brasil to screen health vulnerability in the elderly treated in PHC units and can be easily applied by different professionals of the PHC teams ${ }^{9}$. Older adults with IVCF- $20<7$ are considered robust older adults; with IVCF-20 between 7 and 14, pre-vulnerable; and with IVCF- $20 \geq 15$, vulnerable ${ }^{9-12}$.

Thus, the aim of the present study was to determine the cutoff point for IVCF-20 as a screening test for poor QOL in elderly individuals treated in PHC.

\section{METHODS}

This is a cross-sectional study carried out in the PHC units of Ceilândia, in the Federal District (Brasília, Brasil). Data were collected from September 2019 to January 2020. In 2019, the population of elderly individuals living in Ceilândia was $45,022^{13}$. Thus, considering a $5 \%$ margin of error, a $95 \%$ confidence level, a $50 \%$ prevalence, and a $20 \%$ addition to compensate for any losses, the calculated sample comprised 458 patients. This calculation is in accordance with previous studies on QOL in elderly individuals in $\mathrm{PHC}^{14}$.

Additionally, considering that each Family Health Strategy (FHS) team is responsible for treating the same number of people, patients were selected in each team in the same amount. This division was previously described in a similar study methodology carried out in patients that received care in the $\mathrm{PHC}^{15}$.

The criterion for inclusion was older adults (60 years or older) treated in the PHC units. Individuals with impaired cognitive capacity (defined as those with a score $\leq 9$ at the MiniMental State Examination (MMSE)) were excluded, in addition to those who refused to participate in the study or who did not sign the free and informed consent form. These criteria are in accordance with previously published studies on the elderly in $\mathrm{PHC}^{8,14}$.

Two researchers previously trained to collect data for this research interviewed elderly individuals who met the eligibility criteria for this study. The questionnaire of sociodemographic and clinical data (age, gender, ethnicity, religiousness, schooling, marital status, income, in addition to whether the person lived alone or not) was based on the ELSI study questionnaire ${ }^{16}$.
Health vulnerability was assessed by applying the IVCF20, which is validated for use in the elderly treated in $\mathrm{PHC}^{9-12}$. The questionnaire consists of 20 questions divided into eight sections: age, self-perceived health, functional status, cognition, mood, mobility, communication, and comorbidities. Thus, the calculation of the score is easily performed and has a maximum value of 40 points. Elderly individuals with IVCF- $20 \geq 7$ points are considered pre-vulnerable ${ }^{9-12}$.

The WHOQOL-BREF was used to assess QOL. This questionnaire consists of 26 questions, two of which are general ones, whereas the others cover physical, psychological, social relations and the environmental domains. It is worth recalling that the WHOQOL-BREF was previously validated for Brazilian Portuguese, and previously used to assess QOL for the elderly treated in $\mathrm{PHC}^{6,8,14}$. However, the calculation of the WHOQOL-BREF value is more complex and requires the use of a specific computer program, making it difficult to use it in the daily routine in PHC.

First, the elderly considered as the group with poor QOL (poor QOL) were those who answered "poor" or "very poor" AND "dissatisfied" or "very dissatisfied" to questions 1 and 2 of the WHOQOL-BREF, in accordance with similar PHC studies $^{8,14}$. The group considered to have good QOL (good QOL) consisted of elderly people who answered "good" or "very good" AND "satisfied" or "very satisfied" in questions 1 and 2 of the WHOQOL-BREF ${ }^{8,14}$. The group with undetermined QOL (undetermined QOL) consisted of combinations of answers in questions 1 and 2 that included them neither in poor QOL nor good QOL ${ }^{8,14}$ groups.

After defining the groups, the receiver operating characteristic (ROC) curve was used with the Youden Index. Thus, the IVCF-20 cutoff point was established for poor QOL detection (Case Group: poor QOL; Control Group: good QOL) ${ }^{8}$. In addition, diagnostic tests (sensitivity and specificity) were performed for the poor QOL group in relation to all patients in the study (poor QOL + good QOL + undetermined QOL). A test for poor QOL considered positive had an IVCF-20 score $\geq$ the cutoff point (obtained through the ROC curve); and a test considered negative had the score $<$ the cutoff point. These analyses were also carried out in the same way as other studies of diagnostic tests on QOL in the elderly treated in $\mathrm{PHC}^{8,14}$.

The Shapiro-Wilk test was used to evaluate the data distribution normality. A value of $\mathrm{p}<0.05$ was considered statistically significant. The statistical package Stata version 15.1 (StataCorp LP, College Station, Texas, United States) was used in all analyses.

The study was approved by the Research Ethics Committee of Fundação de Ensino e Pesquisa em Ciências da Saúde under protocol no. 3,497,208. The individuals who agreed to participate and satisfied the eligibility criteria signed the free and 
informed consent form. The study was developed according to the Brazilian Principles of Ethics in Human Research.

\section{RESULTS}

A total of 472 elderly individuals were invited to participate in the study. However, two were excluded due to an MMSE score $\leq 9$ and 12 because they refused to participate in the study. Thus, 458 elderly people were included, which is in agreement with the sample calculation.

Tables 1 and 3 show the sociodemographic characteristics of the sample $(\mathrm{n}=458)$. The following data are highlighted: $66.8 \%$ were women; $63.8 \%$ were of brown and black ethnicity;

Table 1. Sociodemographic and clinical characteristics of 458 patients treated in primary health care. Ceilândia, DF, Brasil, 2019.

Sociodemographic and clinical characteristics

\begin{tabular}{l|c}
\hline Age, median (IQR) & $69(64-74)$ \\
\hline Female gender, n (\%) & $306(66.8)$ \\
\hline Ethnicity, $\mathrm{n}(\%)$ & $165(36)$ \\
\hline Caucasian & $92(20.1)$ \\
\hline Black & $200(43.7)$ \\
\hline Mixed-race & $1(0.2)$ \\
\hline Asian & $416(90.8)$ \\
\hline Religion - very important, n (\%) & $5(3-8)$ \\
\hline Schooling in years, median (IQR) & $344(74,9)$ \\
\hline Perception of insufficient income, n (\%) & $241(52.6)$ \\
\hline Married/Common-law marriage/Lives & $79(17.2)$ \\
\hline with partner, n (\%) & $22(19-24)$ \\
\hline Lives alone, n (\%) & $7(3-12)$ \\
\hline MMSE, median (IQR) &
\end{tabular}

IQR: interquartile; MMSE: mini-mental state examination; IVCF-20: clinicalfunctional vulnerability index-20

Table 2. Results of the Clinical-Functional Vulnerability Index-20 diagnostic tests with cutoff points $\geq 7, \geq 11$ and $\geq 15$ to identify elderly individuals with poor quality of life. Ceilândia, DF, Brasil, 2019.

\begin{tabular}{c|c|c}
$\begin{array}{c}\text { IVCF-20 } \\
\text { cutoff point }\end{array}$ & $\begin{array}{c}\text { Sensitivity (\%) } \\
(95 \% \mathrm{Cl})\end{array}$ & $\begin{array}{c}\text { Specificity (\%) } \\
(95 \% \mathrm{Cl})\end{array}$ \\
\hline$\geq 7$ & $100(96.1-100)$ & $59.7(54.5-64.8)$ \\
\hline$\geq 11$ & $88.1(79.8-93.9)$ & $84.9(80.8-85.4)$ \\
\hline$\geq 15$ & $73.1(62.9-81.7)$ & $97.5 \%(95.3-98.8)$ \\
\hline
\end{tabular}

IVCF-20: clinical-functional vulnerability index-20; Cl: confidence interval.
$90.8 \%$ considered religion to be very important; $74.9 \%$ had insufficient income.

The results of the WHOQOL-BREF were: mean score (standard deviation) was 60.1 (1.2) in the overall domain, 63 (0.6) in the physical domain, $60(0.5)$ in the psychological domain, 62.2 (0.6) in the social domain, and $52.7(0.5)$ in the environmental domain.

Regarding the QOL subgroups, poor QOL had 93 individuals; good QOL, 229; and undetermined QOL, 136. In the IVCF-20 ROC curve, the cutoff point was $\geq 11$ to detect poor QOL and the area under the ROC curve was 0.97 (95\%CI: 0.950.98), as seen in Figure 1. The IVCF-20 diagnostic test (positive for poor QOL when $\geq 11$ ) showed good sensitivity $(88.1 \%)$ and specificity (84.9\%), as seen in Table 2 . Moreover, the sensitivity and specificity values (for poor QOL) using the IVCF-20 values $\geq 7$ and $\geq 15$ (the cutoff points proposed by the authors of the questionnaire for vulnerability detection) are shown in Table 2 .

\section{DISCUSSION}

The main finding of this study was to show, for the first time, that the IVCF-20 can be used to detect poor QOL in elderly individuals in PHC. This instrument was originally validated to screen health vulnerability in older adults in PHC, and the description of its use to screen poor QOL in this scenario is unprecedented. In addition, a score $\geq 11$ at the IVCF- 20 is suggested for poor QOL detection.

Considering the purpose of screening for vulnerability, the author of the IVCF-20 suggests that elderly individuals with scores between 0 and 6 points should be considered robust, while those with scores between 7 and 14 points should be at risk of health vulnerability (pre-vulnerable), and those scoring 15 points or more should be considered vulnerable. In addition, elderly individuals in the subgroup with a score $\geq 15$ should be referred to specialized geriatric outpatient care according to Moraes et al. .

However, we suggest that the elderly individuals with a score $\geq 11$ on the IVCF- 20 should be carefully evaluated either through frequent assessments in PHC (including geriatrics collaborative care) or even referral to specialized geriatric and gerontology outpatient clinics. Our suggested approach is based not only on health vulnerability, but also QOL impairment, which are factors associated with adverse outcomes (e.g. institutionalization, hospitalizations, and death). It is noteworthy that the evaluation of elderly individuals by Geriatrics and Gerontology has already been discussed and suggested in studies related to poor QOL detection in elderly individuals in $\mathrm{PHC}^{8}$.

In view of the need to optimize the use of health services, especially in the Brazilian Unified Health System, we consider 
that the cutoff $\geq 11$ in IVCF-20 is a good option for referring the elderly to be evaluated by geriatrics and gerontology (in a collaborative care or outpatient specialized clinic). This fact is based on the finding that the score $\geq 11$ shows the best association between sensitivity and specificity (the Youden Index) for the screening of elderly individuals with poor QOL. The score $\geq 15$, on the other hand, prioritizes greater specificity, to the detriment of less sensitivity in the screening of such elderly individuals with poor QOL. Thus, the IVCF-20 can have multiple roles, such as those related to health vulnerability and QOL assessment.

Regarding the sociodemographic and clinical characterization of our sample, it was found to be similar to other studies. The characteristics of age, gender, schooling and the fact of living alone were similar to a previous study ${ }^{8,14,17}$. The score found in the WHOQOL-BREF domains were also similar to those obtained in a previous study ${ }^{8,17}$. Hence, further studies will likely have findings similar to those in the present study regarding the role of the IVCF-20 in detecting poor QOL.

As a limitation of this study, we can mention its cross-sectional design. Thus, there is an association between health vulnerability (as measured by the IVCF-20) and poor QOL, but causality cannot be attributed herein. However, previous studies used this cross-sectional design to determine the cutoff point related to poor $\mathrm{QOL}^{8,14}$. Another possible limitation is that, for the first time, an IVCF-20 cutoff point was suggested to identify poor QOL, making it impossible to compare our results with those from other studies. However, such limitation always occurs in studies with unprecedented findings or approaches. Thus, the present study opens up new windows for further external validation research.

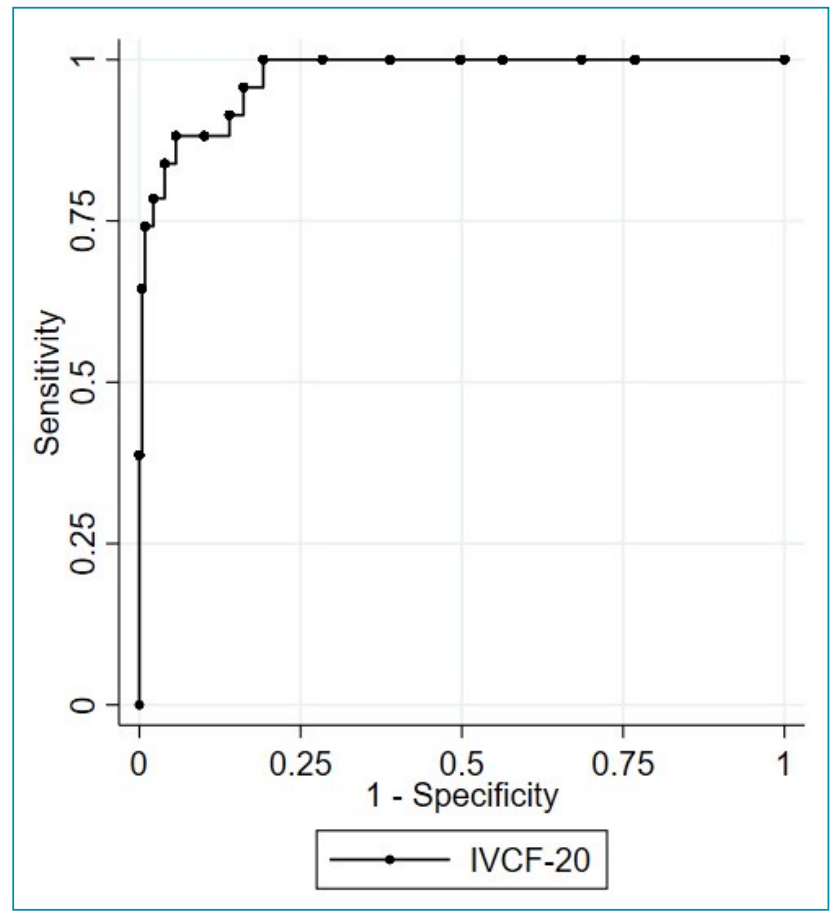

Figure 1. Receiver operating characteristic curve comparing the clinical-functional vulnerability index-20 and poor quality of life.

Table 3. Sociodemographic and clinical characteristics of 458 patients treated in primary health care according to clinicalfunctional vulnerability index-20 groups. Ceilândia, DF, Brasil, 2019.

\begin{tabular}{|c|c|c|c|c|}
\hline \multirow{2}{*}{ Sociodemographic and clinical characteristics } & \multicolumn{4}{|c|}{ IVCF-20 } \\
\hline & $0-6$ & $7-14$ & $\geq 11$ & $\geq 15$ \\
\hline Age, median (IQR) & $69(64-72)$ & $69(65-75)$ & $69(64-75)$ & $69(63-74)$ \\
\hline Female gender, n (\%) & $122(55.9)$ & $116(71.2)$ & $112(81.8)$ & $68(88.3)$ \\
\hline \multicolumn{5}{|l|}{ Ethnicity, n (\%) } \\
\hline Caucasian & $81(37.2)$ & $59(36.2)$ & $52(38.0)$ & $25(32.5)$ \\
\hline Black & $43(19.7)$ & $34(20.9)$ & $29(21.2)$ & $15(19.5)$ \\
\hline Mixed-race & $93(42.7)$ & $70(42.9)$ & $56(40.9)$ & $37(48.0)$ \\
\hline Asian & $1(0.4)$ & $0(0.0)$ & $0(0.0)$ & $0(0.0)$ \\
\hline Religion - very important, $\mathrm{n}(\%)$ & $198(90.8)$ & $147(90.2)$ & $126(92.0)$ & $711(92.2)$ \\
\hline Schooling in years, median (IQR) & $5(3-8)$ & $4(3-8)$ & $4(2-8)$ & $5(1-8)$ \\
\hline Perception of insufficient income, n (\%) & $151(69.3)$ & $128(78.5)$ & $117(84.8)$ & $65(83.3)$ \\
\hline Married/Common-law marriage/Lives with partner, n (\%) & $127(58.3)$ & $81(49.7)$ & $56(40.9)$ & $22(42.9)$ \\
\hline Lives alone, $\mathrm{n}(\%)$ & $40(18.4)$ & $28(17.2)$ & $27(19.7)$ & $11(14.3)$ \\
\hline MMSE, median (IQR) & $22(19-24)$ & $21(18-24)$ & $22(18-24)$ & $21(18-24)$ \\
\hline IVCF-20, median (IQR) & $3(0-5)$ & $9(8-12)$ & $15(13-22)$ & $21(17-24)$ \\
\hline
\end{tabular}

IVCF-20: clinical-functional vulnerability index-20; IQR: interquartile range; MMSE: mini-mental state examination. 


\section{CONCLUSIONS}

This study proposes an IVCF-20 score $\geq 11$ to detect elderly people with poor QOL assisted in PHC. Therefore, in order to further strengthen PHC effectiveness, patients with IVCF$20 \geq 11$ may receive special care, either by attending appointments in PHC or geriatrics/gerontology collaborative care more often. However, further studies are required to validate and corroborate our data.

\section{AUTHORS" CONTRIBUTION}

LBS: Conceptualization, Data Curation, Formal Analysis, Writing - Original Draft, Writing - Review \& Editing. LPB: Conceptualization, Data Curation, Formal Analysis, Writing Original Draft, Writing - Review \& Editing. FFF: Data Curation, Formal Analysis, Writing - Review \& Editing. ANCS: Conceptualization, Data Curation, Formal Analysis, Writing Original Draft, Writing - Review \& Editing.

\section{REFERENCES}

1. Kojima G, lliffe S, Jivraj S, Walters K. Association between frailty and quality of life among community-dwelling older people: a systematic review and meta-analysis. J Epidemiol Community Health. 2016;70(7):716-21. https://doi.org/10.1136/jech2015-206717

2. Miranda GMD, Mendes ACG, Silva ALA. Population aging in Brazil: current and future social challenges and consequences. Rev Bras Geriatr Gerontol. 2016;19(3):507-19. https://doi. org/10.1590/1809-98232016019.150140

3. Almeida-Brasil CC, Silveira MR, Silva KR, Lima MG, Faria CDCM, Cardoso CL, et al. Quality of life and associated characteristics: application of WHOQOL-BREF in the context of primary health care. Cienc Saude Colet. 2017;22(5):170516. https://doi.org/10.1590/1413-81232017225.20362015

4. Bilotta C, Bowling A, Nicolini P, Casè A, Pina G, Rossi SV, et al. Older People's Quality of Life (OPQOL) scores and adverse health outcomes at a one-year follow-up. A prospective cohort study on older outpatients living in the community in Italy. Health Qual Life Outcomes. 2011;9:72. https://doi.org/10.1186/1477-7525-9-72

5. Pereira DS, Nogueira JAD, Silva CAB. Quality of life and the health status of elderly persons: a population-based study in the central sertão of Ceará. Rev Bras Geriatr Gerontol. 2015;18(4):893908. https://doi.org/10.1590/1809-9823.2015.14123

6. Fleck MPA, Louzada S, Xavier M, Chachamovich E, Vieira $G$, Santos L, et al. Aplicação da versão em português do instrumento abreviado de avaliação da qualidade de vida "WHOQOL-bref". Rev Saude Publica. 2000;34(2):178-83. https://doi.org/10.1590/S0034-89102000000200012

7. Capilheira M, Santos IS. Non-communicable chronic diseases: performance of medical care in Primary Health Care in southern Brazil. Cad Saude Publica. 2011;27(6):1143-53. https://doi. org/10.1590/S0102-311X2011000600011

8. Silva SM, Santana ANC, Silva NNBD, Novaes MRCG. VES-13 and WHOQOL-bref cutoff points to detect quality of life in older adults in primary health care. Rev Saude Publica. 2019;53:26. https://doi.org/10.11606/S1518-8787.2019053000802

9. Moraes EN, Carmo JA, Moraes FL, Azevedo RS, Machado CJ, Montilla DE. Clinical-functional vulnerability index-20 (IVCF20): rapid recognition of frail older adults. Rev Saude Publica. 2016;50:81. https://doi.org/10.1590/S1518-8787.2016050006963
10. Maia LC, Colares TFB, Moraes EN, Costa SM, Caldeira AP Robust older adults in primary care: factors associated with successful aging. Rev Saude Publica. 2020;54:35. https://doi. org/10.11606/s1518-8787.2020054001735

11. Barra RP, Moraes EN, Jardim AA, Oliveira KK, Bonati PCR, Issa AC, et al. A importância da gestão correta da condição crônica na Atenção Primária à Saúde para o enfrentamento da COVID-19 em Uberlândia, Minas Gerais. APS em Revista. 2020;2(1):38-43. https://doi.org/10.14295/aps.v2i1.64

12. Brasil. Ministério da Saúde. Nota técnica para organização da rede de atenção à saúde do foco na atenção primária à saúde e na atenção ambulatorial especializada: saúde da pessoa idosa (2019) [Internet]. Sociedade Beneficente Israelita Brasileira Albert Einstein. São Paulo: Hospital Israelita Albert Einstein: Ministério da Saúde; 2019. 56p. [cited on Sept 12, 2020]. Available from: https://atencaobasica.saude. rs.gov.br/upload/arquivos/202001/03091212-nt-saude-doidoso-planificasus.pdf

13. Companhia de Planejamento do Distrito Federal. projeções populacionais para as regiões administrativas do Distrito Federal 2010-2020 [Internet]. Brasília: 2018. [cited on Oct 12, 2020]. Available from: http://www.codeplan.df.gov.br/wp-content/ uploads/2018/02/Projeções-Populacionais-para-as-RegiõesAdministrativas-do-Distrito-Federal-2010-2020.pdf

14. Silva PA, Soares SM, Santos JF, Silva LB. Cut-off point for WHOQOL-bref as a measure of quality of life of older adults. Rev Saude Publica. 2014;48(3):390-7. https://doi.org/10.1590/ s0034-8910.2014048004912

15. Moreschi C, Rempel C, Siqueira DF, Backes DS, Pissaia LF Grave MTQ. Family health strategies: profile/quality of life of people with diabetes. Rev Bras Enferm. 2018;71(6):2899-906. https://doi.org/10.1590/0034-7167-2018-0037

16. Lima-Costa MF, Andrade FB, de Souza PRB Jr, Neri AL, Duarte YAO, Castro-Costa E, et al. The brazilian longitudinal study of aging (elsi-brazil): objectives and design. Am J Epidemiol. 2018;187(7):1345-53. https://doi.org/10.1093/aje/kwx387

17. Tavares DMS, Bolina AF, Dias FA, Ferreira PCS, Haas VJ. Quality of life of elderly. Comparison between urban and rural areas. Invest Educ Enferm. 2014;32(3):401-13. https:// doi.org/10.17533/udea.iee.v32n3a05 